\title{
Evaluation of the antioxidant properties of diarylamines in the benzo $[b \mid$ thiophene series by free radical scavenging activity and reducing power
}

\author{
Isabel C. F. R. Ferreira, ${ }^{\text {a,* }}$ Maria-João R. P. Queiroz, ${ }^{\text {b }}$ Miguel Vilas-Boas, ${ }^{\text {a }}$ \\ Letícia M. Estevinho, ${ }^{a}$ Agathe Begouin ${ }^{\mathrm{b}, \mathrm{c}}$ and Gilbert Kirsch ${ }^{\mathrm{c}}$ \\ ${ }^{a}$ Escola Superior Agrária, Instituto Politécnico de Bragança, Campus de Sta. Apolónia, Apartado 1172, 5301-855 Bragança, Portugal \\ ${ }^{\mathrm{b}}$ Departamento de Química, Campus de Gualtar, Universidade do Minho, 4710-057 Braga, Portugal \\ ${ }^{\mathrm{c}}$ Laboratoire d'Ingénierie Moléculaire et Biochimie Pharmacologique, Faculté des Sciences, Université de Metz 1, \\ bd Arago Metz Technopole, 57078 Metz Cedex 3, France
}

Received 9 November 2005; accepted 10 November 2005

Available online 1 December 2005

\begin{abstract}
The antioxidant properties of substituted diarylamines in the benzo $[b]$ thiophene series were evaluated by their reducing power and free radical scavenging activity. The results were compared with those of standards: acid ascorbic for the first method and BHA and BHT for the second. For both methods it was possible to establish some structure-activity relationships (SARs) based on the position of the arylamination on the benzo $[b]$ thiophene moiety, the presence of different substituents on the phenyl ring $(\mathrm{F}, 1$ or 2 $\mathrm{OMe})$ and on the thiophene ring $\left(\mathrm{H}, \mathrm{CO}_{2} \mathrm{Et}, \mathrm{CO}_{2} \mathrm{H}\right)$.
\end{abstract}

(C) 2005 Elsevier Ltd. All rights reserved.

The search for new molecules with antioxidant properties is a very active domain of research, since they can protect the human body from free radicals and retard the progress of many chronic diseases, such as vascular diseases, some forms of cancer and oxidative stress responsible for DNA, protein and membrane damage. ${ }^{1,2}$ The radical scavenging activity (RSA) using DPPH radical (2,2-diphenyl-1-picrylhydrazyl radical) and the reducing power are two established in vitro methods employed for the evaluation of antioxidant activity. Some authors have observed a direct correlation between antioxidant activities and the reducing power, either for certain plant extracts ${ }^{3}$ or chitosan sulfates. ${ }^{4}$ The presence of reducers (i.e., antioxidants) causes the conversion of the $\mathrm{Fe}^{3+} /$ ferricyanide complex used in this method to the ferrous form. Therefore, by measuring the formation of Perl's Prussian blue at $700 \mathrm{~nm}$ we can monitor the $\mathrm{Fe}^{2+}$ concentration; a higher absorbance at $700 \mathrm{~nm}$ indicates a higher reducing power. The free radical DPPH possesses a characteristic absorption at $517 \mathrm{~nm}$ (purple

$\overline{\text { Keywords: }}$ Diarylamines; Benzothiophenes; Antioxidant activity; Structure-activity relationships.

* Corresponding author. Tel.: +351 273 303219; fax: +351 273 325405; e-mail: iferreira@ipb.pt in colour), which decreases significantly on exposure to radical scavengers (by providing hydrogen atoms or by electron donation). A lower absorbance at $517 \mathrm{~nm}$ indicates a higher radical scavenging activity of the compound. This test is a standard assay in antioxidant activity studies and offers a rapid technique for screening the RSA of pure synthetic compounds. ${ }^{5}$

Herein, we report the reducing power and the free radical scavenging activity of nine diarylamines in the benzo $[b]$ thiophene series, earlier prepared by us, as an evaluation of their in vitro antioxidant activity. Recently, we described the structure-activity relationship of diarylamines $\mathbf{1}$ and $\mathbf{2}$ as antimicrobial agents. ${ }^{6,7}$ However, it is the first time that a study on their antioxidant properties is reported, regarding especially the influence of the compound structure on the results. Differently substituted diarylamine derivatives of 2,3,5-trimethylbenzo $[b]$ thiophene 1a-d were obtained in good to high yields, by $\mathrm{C}-\mathrm{N}$ palladium-catalyzed cross-coupling using either the 6-bromobenzo[b]thiophene or the 6-amino derivative as coupling component (Scheme 1). ${ }^{8}$ The same reaction conditions were also used to obtain diarylamines $\mathbf{2 a}, \mathbf{b}, \mathbf{d}, \mathbf{e}$ in moderate to high yields, coupling ethyl 3-bromobenzo[b]thiophene-2-carboxylate or 


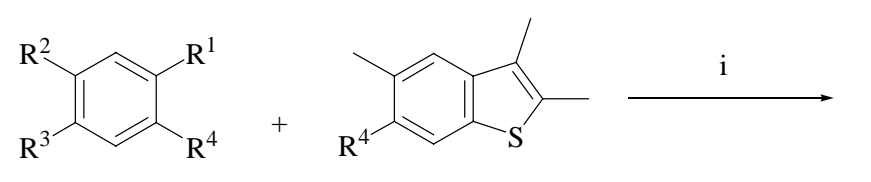<smiles>[R]c1cc(C)c(Nc2cc3sc(C)c(C)c3cc2C)cc1[R]</smiles>

$$
\mathrm{R}^{4}=\mathrm{NH}_{2} \text { or } \mathrm{Br}
$$

1a, $\mathrm{R}^{1}=\mathrm{R}^{3}=\mathrm{H}, \mathrm{R}^{2}=\mathrm{OMe}$

1b, $\mathrm{R}^{1}=\mathrm{H}, \mathrm{R}^{2}=\mathrm{R}^{3}=\mathrm{OMe}$

1c, $R^{1}=R^{3}=H, R^{2}=F$

1d, $R^{1}=F, R^{2}=R^{3}=H$
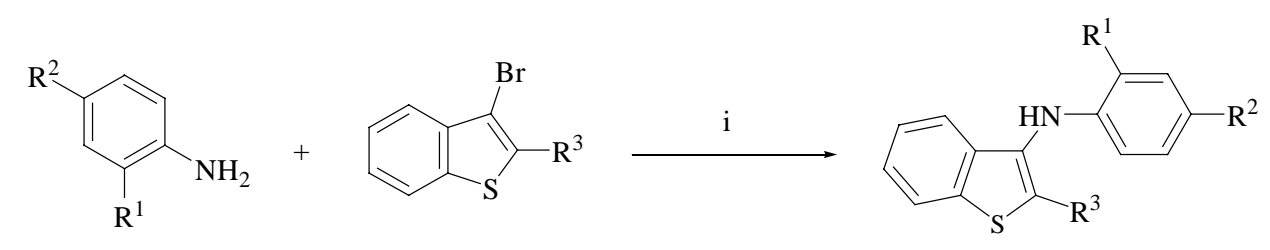

$$
\text { ii } \quad \begin{aligned}
& \text { 2a, } R^{1}=\mathrm{H}, \mathrm{R}^{2}=\mathrm{OMe}, \mathrm{R}^{3}=\mathrm{CO}_{2} \mathrm{Et} \\
& \mathbf{2 b}, \mathrm{R}^{1}=\mathrm{R}^{2}=\mathrm{OMe}, \mathrm{R}^{3}=\mathrm{CO}_{2} \mathrm{Et} \\
& \mathbf{2 c}, \mathrm{R}^{1}=\mathrm{R}^{2}=\mathrm{OMe}, \mathrm{R}^{3}=\mathrm{CO}_{2} \mathrm{H} \\
& \mathbf{2 d}, \mathrm{R}^{1}=\mathrm{R}^{3}=\mathrm{H}, \mathrm{R}^{2}=\mathrm{F} \\
& \mathbf{2 e}, \mathrm{R}^{1}=\mathrm{H}, \mathrm{R}^{2}=\mathrm{F}, \mathrm{R}^{3}=\mathrm{CO}_{2} \mathrm{Et}
\end{aligned}
$$

Scheme 1. Synthesis of diarylamines by palladium-catalyzed arylamination of 2,3,5-trimethylbenzo[b]thiophenes or 3-bromobenzo[b]thiophenes. Reagents and conditions: (i) $\mathrm{Pd}(\mathrm{OAc})_{2}(3 \mathrm{~mol} \%), \mathrm{Cs}_{2} \mathrm{CO}_{3}$ (1.4 equiv), BINAP (4 mol \%), dry toluene, $100{ }^{\circ} \mathrm{C}, \mathrm{Ar}$; (ii) $1-30 \% \mathrm{NaOH}, \mathrm{EtOH}, \Delta$, $2-\mathrm{HCl}(1 \mathrm{~N})$.

3-bromobenzo $[b]$ thiophene with substituted anilines. The carboxylic compound $\mathbf{2 c}$ was obtained in almost quantitative yield by hydrolysis of the ester group of 2b (Scheme 1) ${ }^{7}$

The reducing power of compounds $\mathbf{1}$ and $\mathbf{2}$ was determined according to Oyaizu's method,,${ }^{9,10}$ using ascorbic acid as standard. The capacity of compounds $\mathbf{1}$ and $\mathbf{2}$ to scavenge the 'stable' free radical DPPH was monitored according to Hatano's method, ${ }^{11,12}$ using 2 -tert-butyl4-methoxyphenol (butylated hydroxyanisole, BHA), and 2,6-di-tert-butyl-4-methylphenol (butylated hydroxytoluene, BHT) as standards. Mean values from three independent samples were calculated for each compound with standard deviations less than $5 \%$.

Figure 1 shows the reducing power of methanolic solutions of diarylamines $\mathbf{1}$ and $\mathbf{2}$, examined as a function of their concentration. Compounds $\mathbf{1 a}-\mathbf{c}$ present, at $0.25 \mathrm{~g} / \mathrm{L}$, a reducing power even higher than that of ascorbic acid (1a, 1.66; 1b, 1.79; 1c, 1.37, ascorbic acid, 1.33). In turn, compound 1d shows no reducing power. The presence of a methoxy group in the para position (1a) proved to be better than a $\mathrm{F}$ atom in the same position (1c). The introduction of an additional OMe group (1b) increases the reducing power. The presence of the $\mathrm{F}$ atom in the ortho position (1d) removes the reducing power. For the diarylamines on the thiophene ring, at $0.25 \mathrm{~g} / \mathrm{L}$, the reducing power values for $\mathbf{2 a}, \mathbf{b}, \mathbf{d}$ are higher than 1.20 (2a, 1.21; 2b, 1.28; 2d, 1.33), while for $\mathbf{2 c}$ and $\mathbf{2 e}$ the values are much more lower $(\mathbf{2 c}, 0.89 ; \mathbf{2 e}, 0.33)$. The fluoro compound $\mathbf{2 d}$ presents the higher value in this series and compares to that of ascorbic acid at this concentration. The presence of the ester group in 2e lowers drastically the reducing power. In this series, the introduction of an additional OMe group (2b) increases only slightly the reducing power relatively to diarylamine $\mathbf{2 a}$. The presence of the carboxylic acid group in compound $\mathbf{2 c}$ lowers significantly the reducing power in comparison with the corresponding ester compound $\mathbf{2 b}$ (Fig. 1).

The RSA values for methanolic solutions of diarylamines $\mathbf{1}$ and $\mathbf{2}$ are presented in Table 1 and compared with those of standards BHA and BHT.
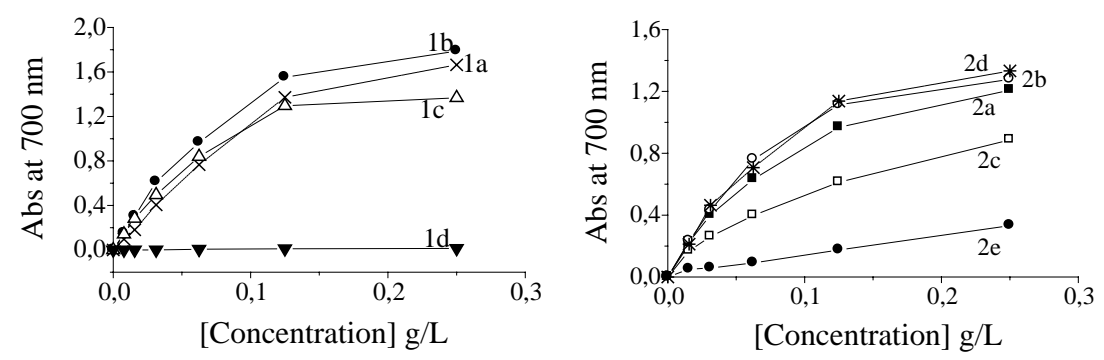

Figure 1. Reducing power of diarylamines 1a-d and 2a-e; ascorbic acid: $\mathrm{Abs}_{700 \mathrm{~nm}}=1.33$ at $0.25 \mathrm{~g} / \mathrm{L}$. 
Table 1. Scavenging activity (\%) on DPPH radicals of diarylamines 1 and 2 and standards BHA, BHT in methanol

\begin{tabular}{lccccc}
\hline Compound & \multicolumn{5}{c}{ Compound concentration $(\mathrm{g} / \mathrm{L})$} \\
\cline { 2 - 6 } & 0.0156 & 0.0312 & 0.0625 & 0.125 & 0.250 \\
\hline 1a & 38.3 & 68.5 & 76.6 & 76.8 & 77.0 \\
1b & 49.0 & 65.3 & 74.6 & 75.0 & 75.4 \\
1c & 0 & 0 & 0 & 0.40 & 2.80 \\
1d & 0 & 0 & 0.52 & 0.54 & 1.21 \\
2a & 0 & 0 & 0.40 & 0.74 & 0.78 \\
2b & 20.8 & 34.8 & 51.1 & 64.7 & 74.8 \\
2c & 8.90 & 30.7 & 44.7 & 63.0 & 84.0 \\
2d & 26.8 & 44.7 & 67.7 & 83.4 & 85.0 \\
2e & 0 & 0.54 & 0.72 & 0.86 & 0.90 \\
BHA & 41.2 & 63.0 & 75.7 & 83.0 & 84.0 \\
BHT & 28.0 & 38.3 & 60.0 & 82.3 & 83.0 \\
\hline
\end{tabular}

The results, in percentage, are expressed as the ratio of the absorbance decrease, at $517 \mathrm{~nm}$, and the absorbance of DPPH solution in the absence of the diarylamines. The analysis of Table 1 leads us to conclude that the RSA of diarylamines on DPPH radicals increases with the increase of the concentration and is higher for compounds $\mathbf{1 a}$ and $\mathbf{b}$ and $\mathbf{2 b - d}$ (74.8$85.0 \%$ at $0.25 \mathrm{~g} / \mathrm{L})$; compounds $2 \mathrm{c}(84.0 \%)$ and $\mathbf{2 d}$ $(85.0 \%)$ reveal a RSA similar to those of standards BHA $(84.0 \%)$ and BHT $(83.0 \%)$ and diarylamines 1a $(77.0 \%), \quad \mathbf{1 b}(75.4 \%)$ and 2b $(74.8 \%)$ present high RSA values but slightly lower than those of the standards. Another observation, regarding RSA efficiency, can be drawn based on the scavenging activity versus the concentration profile: compounds $\mathbf{1 a}$ and $\mathbf{b}$ quickly achieve maximum activity at a low concentration such as $0.0625 \mathrm{~g} / \mathrm{L}$, while, for instance, $\mathbf{2 b}$ needs to be four times more concentrated to achieve the same level. The presence of a $\mathrm{F}$ atom in the diarylamines obtained by amination on the benzene ring (1c and d), removes their scavenging activity on DPPH radicals. Changing the amination to the thiophene ring (2d), the RSA drastically increases to $83.4 \%$ at $0.125 \mathrm{~g} / \mathrm{L}$. Nevertheless, the corresponding ester compound $\mathbf{2 e}$ is not effective at scavenging DPPH radicals. The presence of $\mathrm{OMe}$ groups seems to contribute to the good results of RSA on both series; however, the presence of an ester group on compound 2a significantly alter this behaviour and the RSA almost vanished. For diarylamines with two OMe groups in the ortho and para positions, the carboxylic compound $\mathbf{2 c}$ shows a RSA value $(84.0 \%$ at $0.25 \mathrm{~g} / \mathrm{L})$ higher than that of the corresponding ester $\mathbf{2 b}(74.8 \%$ at $0.25 \mathrm{~g} / \mathrm{L})$ but for both compounds the results are good (Table 1).

In conclusion, the antioxidant properties of several substituted diarylamines in the benzo[b]thiophene series, aminated either on the benzene moiety (compounds 1) or on the thiophene ring (compounds 2), previously prepared by us, seem to be dependent on the type of substituents and their position. Some compounds have shown a good antioxidant activity, evaluated in terms of reducing power and RSA, even better than those of the well-known antioxidants ascorbic acid, BHA or BHT. Compounds 1 gave better reducing power results than compounds
2, excluding 1d. In general for diarylamines $\mathbf{1}$ and 2, the presence of electron-donating groups ( 1 or 2 $\mathrm{OMe}$ ) increases the reducing power. The $\mathrm{F}$ atom in the para position relative to the $\mathrm{N}-\mathrm{H}$ bond (1c and 2d) also gave good results, possibly due to its electron-donating mesomeric effect $(+M)$. On the other side, compound 1d with the $\mathrm{F}$ atom in the ortho-position has no reducing power. In this case, the electron-withdrawing inductive effect $(-\mathrm{I})$ can be the electronic effect prevailing. An intramolecular $\mathrm{H}$-bond involving the $\mathrm{F}$ atom and the $\mathrm{N}-\mathrm{H}$ may also be a possible explanation for the absence of the reducing power of 1d. The RSA values were strongly affected by the presence of an ester group at the 2-position of the thiophene ring in diarylamines 2. The $p$-methoxy and $p$-fluoro compounds present no RSA, maybe as a consequence of the electron-withdrawing effect of the ester group or due to intramolecular $\mathrm{H}$-bonds between the $\mathrm{NH}$ and the carbonyl group. Nevertheless, for the compound with two OMe groups (2b) these effects were not important and the same was observed for the corresponding acid carboxylic compound (2c), both giving good RSA results.

\section{Acknowledgments}

The authors thank the Foundation for Science and Technology (Portugal), for financial support through CQ-Univ. Minho and CIMO-ESA Bragança, Calouste Gulbenkian Foundation (Portugal) for the financial support through the Research Incitement Programme.

\section{References and notes}

1. Halliwell, B.; Gutteridge, J. M. C. In Free radicals in Biology and Medicine, 3rd ed.; Oxford University Press: Oxford, 1999.

2. Nakayama, T.; Yamada, M.; Osawa, T.; Kawakishi, S. Biochem. Pharmacol. 1993, 45, 265.

3. Pin-Der-Duh, X.; Pin-Chan-Du, X.; Gow-Chin-Yen, X. Food Chem. Toxicol. 1999, 37, 1055.

4. Xing, R.; Yu, H.; Liu, S.; Zhang, W.; Zhang, Q.; Li, Z.; Li, P. Bioorg. Med. Chem. 2005, 13, 1387.

5. Amarowicz, R.; Pegg, R. B.; Rahimi-Moghaddam, P.; Barl, B.; Weil, J. A. Food Chem. 2004, 84, 551.

6. Ferreira, I. C. F. R.; Calhelha, R. C.; Estevinho, L. M.; Queiroz, M.-J. R. P. Bioorg. Med. Chem. Lett. 2004, 14, 5831.

7. Queiroz, M.-J. R. P.; Begouin, A.; Ferreira, I. C. F. R.; Kirsch, G.; Calhelha, R. C.; Barbosa, S.; Estevinho, L. M. Eur. J. Org. Chem. 2004, 3679.

8. Ferreira, I. C. F. R.; Queiroz, M.-J. R. P.; Kirsch, G. Tetrahedron 2003, 59, 975.

9. Oyaizu, M. Jpn. J. Nut. 1986, 44, 307.

10. Several concentrations of methanolic solutions of compounds 1 and 2 (Fig. 1) $(2.5 \mathrm{~mL}$ ) were mixed with $2.5 \mathrm{~mL}$ of $200 \mathrm{mmol} / \mathrm{L}$ sodium phosphate buffer $(\mathrm{pH}$ 6.6) and $2.5 \mathrm{~mL}$ of $1 \%$ potassium ferricyanide. The mixture was incubated at $50{ }^{\circ} \mathrm{C}$ for $20 \mathrm{~min}$. Afterwards, $2.5 \mathrm{~mL}$ of $10 \%$ trichloroacetic acid $(\mathrm{w} / \mathrm{v})$ was added and the mixture was centrifuged at $650 \mathrm{rpm}$ for $10 \mathrm{~min}$. The upper layer $(5 \mathrm{~mL})$ 
was mixed with $5 \mathrm{~mL}$ of deionised water and $1 \mathrm{~mL}$ of $0.1 \%$ ferric chloride, and the absorbance was measured at $700 \mathrm{~nm}$.

11. Hatano, T.; Kagawa, H.; Yasuhara, T.; Okuda, T. Chem. Pharm. Bull. 1988, 36, 2090.

12. Several concentrations of methanolic solutions of compounds 1 and $\mathbf{2}$ (Table 1) were prepared. The compound solution $(0.3 \mathrm{~mL})$ was added to the methanolic DPPH solution $\left(2.7 \mathrm{~mL}, 6 \times 10^{-5} \mathrm{~mol} / \mathrm{L}\right)$ and the mixture was kept in the dark for $60 \mathrm{~min}$. The absorbance at $517 \mathrm{~nm}$ was then measured. The RSA was calculated as a percentage of DPPH decolouration using the equation: $\% \mathrm{RSA}=100 \times\left(1-A_{\mathrm{c}} / A_{\mathrm{D}}\right)$, where $A_{\mathrm{c}}$ is the solution absorbance measured when a compound was added at a particular concentration and $A_{\mathrm{D}}$ is the absorbance of the DPPH solution. 